\title{
PENGENDALIAN EMISI MERKURI DI CEROBONG INDUSTRI PADA PENGGUNAAN BATU BARA SEBAGAI BAHAN BAKAR
}

\author{
Isa Ansyori ${ }^{1}$ \\ (Diterima tanggal : 03-01-2011; Disetujui tanggal : 18-05-2011)
}

\begin{abstract}
The mercury emission control in coal depends on several factors including type of coal, emission control equipment, configuration, mixing 2 types of coal, and the use of Active Carbon Injection Technologies.
\end{abstract}

Keywords: Mercury emissions, coal, emissions control.

\begin{abstract}
ABSTRAK
Pengendalian emisi merkuri pada pemanfaatan batu bara sebagai bahan bakar bergantung beberapa faktor yaitu jenis batubara, alat pengontrol emisi, pencampuran 2 jenis batubara, dan penggunaan teknologi injeksi karbon aktif (Activated Carbon Injection).
\end{abstract}

Kata kunci: Emisi merkuri, batubara, pengontrol emisi.

\section{PENDAHULUAN}

Merkuri merupakan logam berat yang berbahaya bagi kesehatan dan lingkungan hidup. Merkuri berbahaya bagi lingkungan karena bersifat persisten. Karena berbahaya merkuri telah diatur di peraturan pemerintah.. Di dalam peraturan pemerintah tersebut bahan yang berbahaya dan beracun terbatas untuk digunakan. Sumber - sumber merkuri yang dilepaskan ke lingkungan antara lain dari pengolahan emas, almalgam gigi dan pembakaran batubara.

Emisi merkuri yang dihasilkan dari pembakaran batubara seperti pada unit boiler harus diperhatikan karena berpotensi untuk merusak lingkungan dan menjadi ancaman bagi kesehatan makhluk hidup. Jenis merkuri yang diemisikan ke udara bervariasi yaitu dalam bentuk uap merkuri $\left(\mathrm{Hg}^{\circ}\right)$, Oksida merkuri dan partikulat. Uap merkuri $\left(\mathrm{Hg}^{\circ}\right)$ mempunyai waktu tinggal yang lama di udara yaitu bisa mencapai satu tahun, sehingga dapat menyebar pada jarak yang sangat jauh dari sumbernya. Ketika $\mathrm{Hg}^{\circ}$ terdeposit di tanah atau air , maka dapat mengalami transformasi menjadi merkuri organik yaitu metil merkuri yang dapat memasuki rantai makanan seperti ikan.

Pengendalian merkuri dari cerobong pembakaran batubara belum dilakukan penelitian, maka perlu dilakukan penelitian mengenai pengendalian dan efektifitasnya.

\section{METODOLOGI DAN TUJUAN}

Metode yang digunakan yaitu observasi di PLTU Unit Bisnis Pembangkitan Listrik PT. Indonesia Power Suralaya, data sekunder dari literatur dan pengambilan contoh uji mekuri di cerobong 6 PLTU Suralaya dengan metode 29 USEPA yang dilakukan pada 4 November 2010 .

\footnotetext{
${ }^{1}$ Fungsional Pedal Pusat Sarana Pengendalian Dampak Lingkungan-Deputi VII KLH, Kawasan Puspiptek Gedung 210, Serpong, Banten, 15310-Indonesia.isaansori70@yahoo.com
} 
Tujuan untuk mengetahui efektifitas pengendalian merkuri di cerobong pada pembakaran batubara terhadap emisi merkuri.

\section{HASIL DAN PEMBAHASAN}

Batubara di unit bisnis pembangkitan listrik Suralaya yang digunakan sebagai bahan bakar yaitu subbituminous dari Sumatera Selatan dan digunakan Low NOx Burners.

Batu bara digiling menjadi serbuk. Serbuk batubara dicampur dengan udara panas dari Primary Air Fan dan dibawa ke Coal Burner yang menyemburkan batubara tersebut ke dalam ruang bakar untuk proses pembakaran dan terbakar seperti gas, untuk mengubah air menjadi uap.

Udara pembakaran yang digunakan pada ruang bakar dipasok dari Forced Draft Fan (FDF) yang dialirkan melalui Air Heater. Hasil proses pembakaran yang terjadi menghasilkan limbah berupa abu. Abu secara periodik dikeluarkan ke Ash Valley.

Debu dan gas hasil pembakaran dihisap keluar dari boiler oleh Induce Draft Fan (IDF) dan dilewatkan melalui Electrostatik Presipitator. Debu yang terkumpul di Electrostatik Presipitator diambil dengan alat pneumatic gravity conveyor selanjutnya dihembuskan ke udara melalui cerobong.

Pengukuran merkuri dilakukan pada ketinggian $121 \mathrm{~m}$ dengan 4 lubang sampling. Data yang didapat yaitu $0,028 \mathrm{mg} / \mathrm{dsm}$ atau 0.0003 $\mathrm{mg} / \mathrm{m}^{3}$.

Data pengukuran tersebut hampir sama dengan penelitian di Cleveland Ohio Amerika dari inlet dan outlet RE Burger Plant dengan teknologi Elecktro Catalitic Oxidation pada table 1. Teknologi ECO merupakan gabungan
Fabrik Filter dan Elektrostatik Presipitator ${ }^{(1)}$ .(7).

Tabel 1. Data Reduksi Merkuri dengan Teknologi ECO

\begin{tabular}{|c|c|c|}
\hline $\begin{array}{c}\text { Inlet } \\
\mathrm{mg} / \mathrm{m} 3\end{array}$ & $\begin{array}{c}\text { Out let } \\
\mathrm{mg} / \mathrm{m} 3\end{array}$ & $\begin{array}{c}\text { \% Reduksi } \\
\text { merkuri }\end{array}$ \\
\hline 0.0069 & 0.00078 & $88 \%$ \\
\hline
\end{tabular}

Faktor-faktor yang mempengaruhi jumlah emisi merkuri dari cerobong udara yaitu jenis batubara, alat pengontrol emisi dan pencampuran 2 jenis batubara, serta penggunaan teknologi injeksi karbon aktif (Activated Carbon Injection).

\section{Konfigurasi Alat dan Jenis Batubara}

Pengontrol merkuri pada emisi cerobong bahan bakar batu bara yaitu :

1. Teknologi co benefit yaitu teknologi yang didesain untuk mengontrol polutan lain selain merkuri, yaitu NOx, SOx dan bahan partikulat (PM) tetapi dalam hal ini dapat juga digunakan sebagai alat pengontrol merkuri(2) .

NOx dapat dikontrol menggunakan pengendap elektrostatik (Elektrostatik Presipitator). Selain berfungsi sebagai pengontrol NOx, Electrostatik Presipitator dapat juga digunakan sebagai pengontrol emisi merkuri dengan cara mengoksidasi uap merkuri. SOx adalah polutan yang dikontrol menggunakan Wet Scrubber Gas Desulfurization). Selain berfungsi sebagai pengontrol SOx, Wet Scrubber Gas Desulfurization dapat juga digunakan sebagai pengontrol emisi 
merkuri dengan cara melarutkan Oksida merkuri di dalam air(5)(2). Bahan partikulat (PM), baik yang berasal dari partikulat merkuri atau partikulat lain dapat dikontrol dengan alat seperti CS-Elektrostatic Presipitator HSElektrostatic Presipitator, Fabrik Filter dan Scrubber debu ${ }^{(6)}$.

Pada tabel 2 terlihat bahwa alat pengontrol polutan yang paling efisien untuk batubara bituminous adalah Fabrik Filter dengan jumlah merkuri yang dibuang 1,78 \%. Dari tabel 3 terlihat bahwa konfigurasi alat pengontrol polutan yang paling efisien untuk batubara sub-bituminous adalah Fabrik Filter dengan jumlah merkuri yang dibuang 27,57\%. Dari tabel 4 terlihat bahwa konfigurasi alat pengontrol polutan yang paling efisien untuk batubara lignit adalah ESP dan Wet Scrubber dengan jumlah merkuri yang dibuang $62,52 \%$.

Tabel 2. Pengaruh alat pengontrol polutan terhadap jumlah merkuri yang dibuang ke udara untuk batu bara bituminous

\begin{tabular}{|c|l|c|}
\hline $\begin{array}{c}\text { Jenis } \\
\text { Batubara }\end{array}$ & $\begin{array}{c}\text { Alat Pengontrol } \\
\text { Pencemar } \\
\text { Udara }\end{array}$ & $\begin{array}{c}\text { \% Merkuri } \\
\text { yang dibuang } \\
\text { ke udara }\end{array}$ \\
\hline \multirow{5}{*}{ Lignit } & CS/ESP dan Wet & 62,52 \\
& FGD Scrubber & 67,23 \\
& SDA-FF & 82,62 \\
& CS-ESP dan FF & 67,38 \\
& SDA/FF & 95,07 \\
& SM & 98,53 \\
\hline
\end{tabular}

\section{Teknologi Activated Carbon Injection (ACI)}

Teknologi yang spesifik untuk merkuri yaitu injeksi karbon aktif (Activated Carbon Injection) yaitu

Tabel 3. Pengaruh alat pengontrol terhadap jumlah merkuri yang dibuang ke udara untuk batubara subbituminous

\begin{tabular}{|c|l|c|}
\hline $\begin{array}{c}\text { Jenis } \\
\text { Batubara }\end{array}$ & $\begin{array}{c}\text { Alat Pengontrol } \\
\text { Pencemar } \\
\text { Udara }\end{array}$ & $\begin{array}{c}\text { \% Merkuri } \\
\text { yang dibuang } \\
\text { ke udara }\end{array}$ \\
\hline \multirow{5}{*}{ Bituminous } & SDA/FF & 1,78 \\
& SCR dan SDA/FF & 2,44 \\
& CS-FF dan FGD & 3,59 \\
& Scrubber & 9,1 \\
& SNCR dan CS-ESP & 16,90 \\
& FF & 18,77 \\
& Wet FGD Scrubber & 44,95 \\
& HS-ESP Wet FGD & 53,52 \\
& Scrubber & 55,11 \\
& CS-ESP & 87,98 \\
\hline
\end{tabular}

Tabel 4. Pengaruh alat pengontrol terhadap jumlah merkuri yang dibuang ke udara untuk batubara lignit

\begin{tabular}{|c|l|c|}
\hline $\begin{array}{c}\text { Jenis } \\
\text { Batubara }\end{array}$ & $\begin{array}{c}\text { Alat Pengontrol } \\
\text { Pencemar } \\
\text { Udara }\end{array}$ & $\begin{array}{c}\text { \% Merkuri } \\
\text { yang dibuang } \\
\text { ke udara }\end{array}$ \\
\hline & CS/FF & 27,57 \\
& CS-ESP/ SDA & 62,06 \\
Sub & CS-ESP dan Wet & 64,88 \\
bituminous & FGD Scrubber & 67,38 \\
& HS-ESP dan Wet & 74,60 \\
& FGD Scrubber FF & 85,52 \\
& SDA/FF & 86,54 \\
& CS-ESP & 85,57 \\
\hline
\end{tabular}


penginjeksian karbon aktif kering berbentuk bubuk ke dalam cerobong. ACI ditempatkan antara pemanas udara (air preheater) dan Electrostatik Presipitator atau Fabrik Filter. Hasil penelitian pengaruh kecepatan injeksi karbon aktif terhadap \% merkuri menggunakan 2 alat pengontrol polutan yaitu Electrostatik Presipitator dan Fabrik Filter untuk batu bara bituminous dan sub bituminous, pada Gambar $1^{(1)}$.

Keterangan:

CS-ESP : Cold-Side Electrostatic Precipitator

SCR : Selective Catalitic Reduction

HS-ESP : Hot-Side Electrostatic Precipitator

FGD : Flue gas Desulfurization

FF : Fabric Filter

SNCR : Selective Non Catalitic Reduction

PM : Pariculate Matter

DSI : Duct Sorbent Injection

SDA :Spray Dryer Absorber

Pada gambar 1 terlihat bahwa untuk alat pengontrol ESP pada batubara bituminous, pengurangan merkuri sampai dengan $90 \%$ dapat tercapai pada kecepatan injeksi karbon aktif sekitar $20 \mathrm{lb} /$ Macf (million actual cubic feet) sedangkan untuk alat pengontrol FF untuk batubara yang sama penangkapan merkuri sampai dengan 90\% dapat tercapai pada kecepatan injeksi 4 lb/ Macf $^{(1)}$. Untuk mencapai $90 \%$ pengurangan merkuri, diperlukan 5 kali lebih banyak penyerap karbon aktif bila menggunakan ESP dibanding FF. Hal ini disebabkan karena terbentuknya lapisan karbon pada fabrik filter sehingga penyerapan lebih maksimal ${ }^{(2)}$. Pada penggunaan alat pengontrol ESP untuk jenis batubara sub bituminous diperoleh hasil bahwa pengurangan emisi maksimum sekitar $60 \%$ dan terjadi mulai dari kecepatan injeksi sekitar 7 lb/Macf. Kenaikan kecepatan injeksi karbon aktif tidak dapat menaikkan persentase pengurangan merkuri.

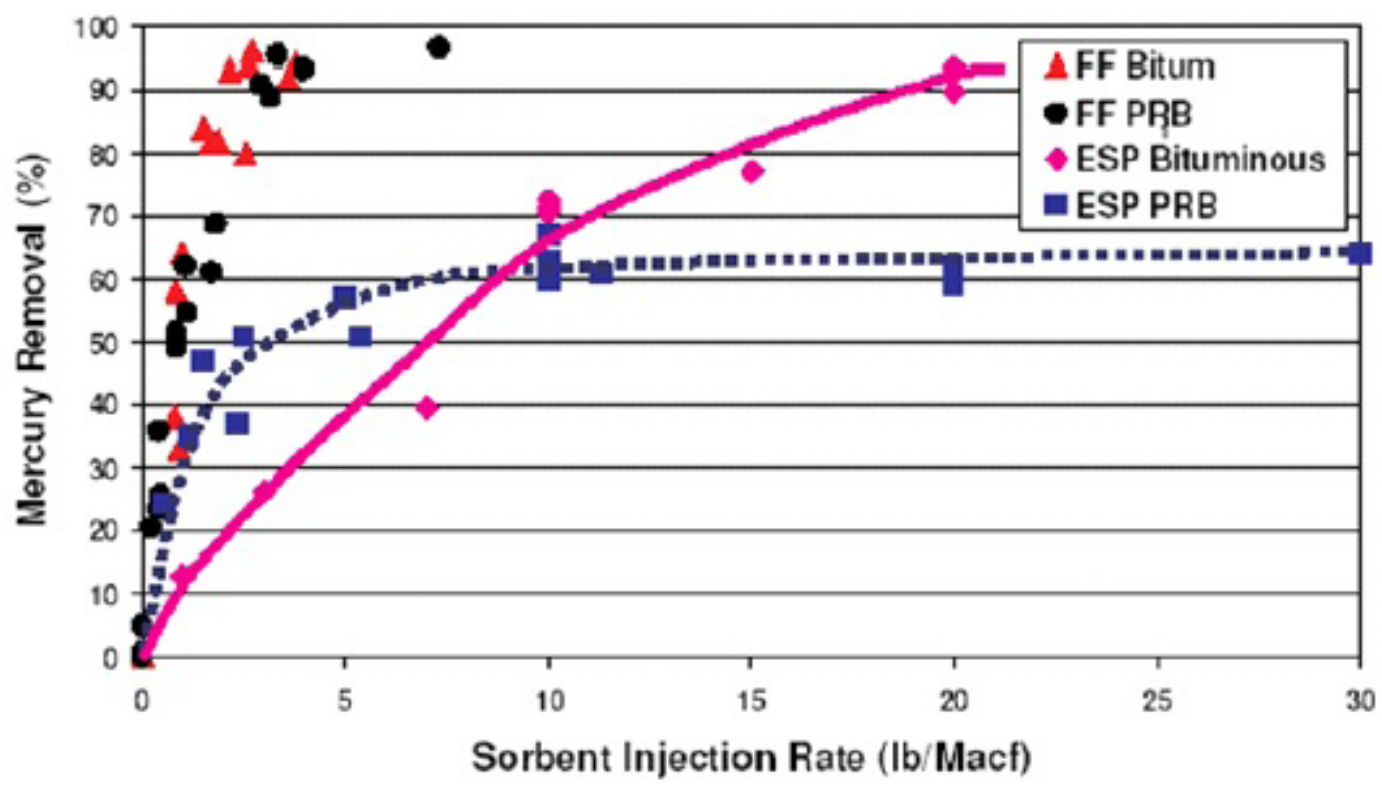

Gambar 1. Pengaruh kecepatan injeksi karbon aktif terhadap \% pengurangan merkuri 


\section{Pengaruh pencampuran 2 jenis batubara}

Untuk meningkatkan kemampuan penangkapan merkuri dengan mencampurkan 2 jenis batubara yaitu batubara yang mengandung klorin atau bromin yang tinggi dengan batubara yang mengandung klorin atau bromin rendah.

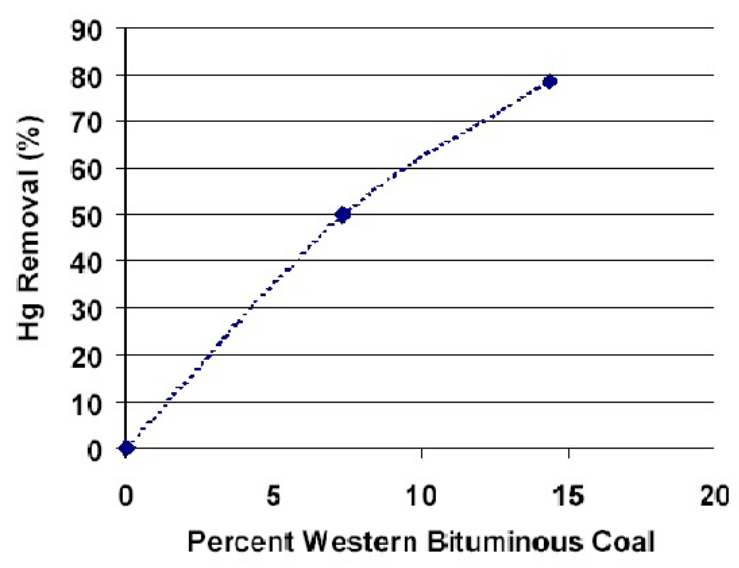

Gambar 2. Hubungan batubara bituminous berklorin tinggi dengan \% pengurangan merkuri.

Pada Gambar 2 memperlihatkan pengaruh pencampuran batubara bituminous berkadar klorin tinggi dengan batubara sub bituminous berkadar klorin rendah, bertambahnya komposisi batubara bituminous dalam campuran maka semakin besar persentase merkuri yang dapat yang diadsorsi ${ }^{(1) .}$

\section{KESIMPULAN}

Emisi merkuri yang paling rendah dari cerobong pada pembakaran batubara yaitu terjadi pada batubara bituminous dan sub bituminous dengan fabric filter, serta batubara lignit dengan ESP dan Wet Scubber.

\section{DAFTAR PUSTAKA}

1.Durham, M.D., 2005. "Mercury Control for PRB and PRB/Bituminous Blends" www.icac.com.

2.Praveen, A., 2003, "Mercury Emissions From Coal- Fired Power Plants", www.nescaum.org.

3.Boilers", Century: Impacts of Fuel Quality and Operations Engineering Foundation Conference, Snowbird, UT, www.reaction_eng.com.

4.Zhuang, Y., 2006 , Mercury Transformations in Coal Combustion Flue Gas", www.undeerc.org.

5.Environmental Protection Agency, 2003, "Performance and Cost of Mercury and Multi pollutant Emission Control Technology Aplication on Electric Utility Boilers", EPA/600/R-03/110, www.epa.gov.

6.Environmental Protection Agency, 2000, "Electric Utility Steam Generating Units Hazardous Air Pollutant Emission Study (Mercury ICR),

7. David CF, 2005. Air Pollution Control and Monitoring Technology. www. icac.com.

8. US-EPA Method 29 - Determination of Metals Emissions from Statioanry Sources.

9. Kep-205/BAPEDAL/07/1996 Tentang Pedoman Teknis Pengendalian Pencemaran Udara Sumber Tidak Bergerak, BAPEDAL 